\title{
SET-TOP BOX AND ITS PENETRATION IN THE HOME CONSOLE MARKET
}

\author{
Tuan-Vinh Le \\ Chang Gung University \\ tvle.cgu@gmail.com \\ Chih-Chin Liang \\ National Formosa University \\ lgcwow@gmail.com
}

\begin{abstract}
Based on Unified Theory of Acceptance and Use of Technology model (UTAUT) and Perceived Value and Loyalty model (PVL), this study developed two new models, New Technology Device Acceptance model (NTDA) and Technology Experience and Loyalty model (TEL) in order to investigate the customer intention to use (before purchase) and reuse intention (after purchase) the set-top box. The analytical results indicate that there has a positive influence of performance expectancy, effort expectancy, social influence, competitive product, price, promotion and behavioral intention on customer use intention. Similarly, the positive influences of usefulness, facilitating effect, connectedness, access flexibility, application development, game experience, application price and post purchase promotion on customer reuse intention are also indicated.
\end{abstract}

Keywords: Set-Top Box, Home Console, Use Intention, Reuse Intention

\section{INTRODUCTION}

Home console market is growing up very fast. There are a lot of manufacturers who are developing their products and competing with each other over the world, among them, Sony and Microsoft are two biggest players. Their products, Xbox (Microsoft) and PlayStation (Sony), have dominated home console market for decades. They are definitely two gaming machines which have powerful hardware for the best performance and get attracted by a huge number of fans over the world [1]. According to Super Data Research in 2015, PlayStation is more attractive with 63\% of total revenue compared to $37 \%$ of Xbox. The set-top box (STB) market has grown and changed significantly over the past years.

The STB market is now dominated by Apple and Google. With the great determination, Apple has introduced their latest product, the long awaited fourth generation Apple TV at its "Hey Siri" media event on September 9, 2015, giving the world an updated look at Apple's vision of the ideal television experience. The Apple TV, which connects via HDMI to compatible television sets, focuses on what Apple says is the foundation of a great STB: powerful hardware, a modern operating system, a fun and easy user experience, powerful tools for developers to create Apps, and a 
dedicated App Store. Combined, these factors are aimed at expanding the available content on the Apple TV and making it easy for users to sort through that content to find new movies to watch, new TV shows to follow, and new games to play. For Google, Android is an open operating system, so, there are so many Android TV devices produced by lots of manufacturers through the world. Probably, the best well-known Android devices are Nvidia Shield. Nvidia Shield has also introduced a series of Android TV products in recent years. Nvidia Shield provides us the wonderful performance of HD movies, game capabilities, voice or video call, YouTube, karaoke, surfing website, and social networks [2].

The STB is a modern technology product included in electronic commerce. In Vietnam and Taiwan, electronic commerce has been more and more developed. Vietnam has had good steps in term of expanding internet and technology field. The BKAV cooperation released BPhone which is a Vietnamese smart phone. Despite unexpected revenue, it contributed to push Vietnam digital market. Flappy bird, a worldwide famous mobile game was developed by Dong Nguyen, Vietnamese developer of dotGEARS company. For Taiwan, high-tech industry has been growing for years. Taiwan has famous brands such as Foxconn, HTC, Asus, Acer which earned big reputation for smart phone, computer mainboard, and notebook in the world. Although Vietnam-Taiwan relations are conducted on unofficial level for years, this has not stopped bilateral visits and significant flows of migrants and investment capital between two countries [3]. Taiwan represented the largest source of foreign direct investment in Vietnam since 2006 [4]. For electronic commercial market particularly, Vietnam and Taiwan have had important advances recently. This study hopes to be a one of the bridges of technology market relationship between two countries by studying the penetration of STB into Home Console market. It should be good for both Vietnam and Taiwan. For Vietnamese, a research show that the dependency on TV of people is very high, especially for the people aging over 40 [5]. Averagely, each of Vietnamese people owns 1.7 TV devices, among them, each of single owns 1.5 TV devices and each of married ones owns 1.9 TV devices [6]. It indicates that TV market is very potential in Vietnam and STB will be a good choice for both manufactures and customers. For Taiwan, the percentage of STB users have also increased from $4 \%$ to $13 \%$ for recent years [7]. Famous technology corporations in Taiwan can also take advantage of STB to diversify their business and help customer have one more useful product when intending to experience technology.

As a result, this research study is truly needed. This paper introduced a study consisting of two analyses: before-purchase and after-purchase studies. The before-purchase analysis (performance expectancy, effort expectancy, social influence, competitive products, price and promotion, behavioral intention and use intention) shows how customer accept to use the new STB, whether or not they should pay for STB. The after-purchase analysis (usefulness, facilitating effects, connectedness, access flexibility, application development, game experience, Apps price, post purchase promotion and reuse intention) indicates how they feel after using it and how their STB loyalty is. 


\section{SET-TOP BOX IN TAIWAN AND VIETNAM}

A study by [8] was conducted to find the connection between set-top box and digital cable television service. They are typically regarded as a way of managing TVs programs. Moreover, [9] indicated that a series of STB brands (such as VTC, FPT, VASC) which employs Android OS were released, which contributes to a thriving STB entertainment. Vietnamese manufacturers have the ability to make STBs which satisfies the requirements set by the Ministry of Information and Communication. Another research [10] was conducted to study about the illegal hacking into IPTV systems. Aforementioned reports indicated that set-top box and the Internet TV have become prevalent in Vietnam.

Apple TV has been on sale in Taiwan and even on Apple's official website in recent years. With the popularization of Digital TV in the family, the STB is gradually entering families scale. The compatibility of software and hardware make the STB a more popular device in many families. [11] discussed about the feasibility of a family network with the STB as a gateway. [12] mentioned about the strategy research of Taiwan multimedia fabless IC industry by the STB development experiences.

\section{Research Framework and hypotheses}

In this study, two research models have been adopted to find the factors influencing use and reuse intention of STB.

\subsection{Before purchase}

This study proposed New Technology Device Acceptance model (NTDA) for the use of STB before purchase. A new trend of using TV today is that the TV which can be connected with the Internet and its operation system is consistent with Apps system [13]. The future TV integrated with STV can satisfy customers' entertainment requirements, such as watching $\mathrm{TV}$, using social network, listening music, reading article, news, and even composing documents [14]. Thus, this study proposed the following hypothesis.

\section{H1. Performance expectancy positively influences behavioral intention.}

Along with the increasing customer needs, features like chatting, broadcasting wireless network or saving data are also very necessary for a modern life with a modern device [15]. Thus, this study proposed the following hypothesis.

\section{H2. Effort expectancy positively influences behavioral intention.}

When users feel that they are connected with other friends via a social game, they may be willing to remain on the game, and even pay for it [16]. Thus, this study proposed the following hypothesis.

\section{H3. Social influence positively influences behavioral intention.}

Loyal customers often bring in substantial revenue. Moreover, they also tend to use the product with the same brand as their existing devices for the convenience of being successfully synchronizing purchased Apps [17]; [16]. Thus, this study proposed the following hypothesis. 


\section{H4. Competitive product positively influences behavioral intention.}

If customers feel that STB they used was worth the price, their perception of the received value will be high [16]. In addition, customers usually consider that whether the price is over their budget before making a purchase [18]. Thus, this study proposes the following hypothesis.

\section{H5. Price positively influences use intention.}

The promotion is also a sensitive consideration for customers [19]; [20]. Thus, this study proposes the following hypothesis.

\section{H6. Promotion positively influences use intention.}

The behavior influence customer acceptance and usage of the STB [16]; [21]. Customer behavior to the STB drives their use intention [16]. Thus, this study proposed the following hypothesis.

H7. Behavioral intention positively influences use intention.

\subsection{After purchase}

This study proposed Technology Experience and Loyalty model (TEL) for the evaluation after purchase. The features of STB have already attracted customers eyeballs. It is a device of useful entertainment that customers want to use it continuously [16]. Thus, the following hypothesis is proposed.

H8. Usefulness of features positively influences reuse intention.

For customers, the storage size is really necessary for STB. The customer-cared facilitating effects must be secured and satisfied for all customer requirements [22]. Thus, this study proposed the following hypothesis.

\section{H9. Facilitating effects positively influences reuse intention.}

After purchasing STB, customers and their family members/friends satisfied with the meeting/conference/connection by using STB [23]. Thus, this study proposed the following hypothesis.

\section{H10.Connectedness positively influences reuse intention.}

Access flexibility make user's comfortable perception. Customers can easily use STB with the connection with a monitor or TV [16]. Thus, the following hypothesis is proposed.

H11. Access flexibility positively influences reuse intention.

The manufactures of STB also show that the hardware must be with the newest and updated applications [24]. Thus, this study proposed the following hypothesis.

\section{H12. Application development positively influences reuse intention.}

The use of STB games is significantly influenced by customer experiences on PlayStation and Xbox games [25]. Thus, this study proposes the following hypothesis.

H13.Game experience positively influences reuse intention. 
If most of the price of applications is acceptable, customers might wish to buy it and use the STB [16]. Thus, this study proposed the following hypothesis.

\section{H14. Application price positively influences reuse intention.}

The post purchase support might provide customers the chance to exchange the old device with the new one with a reasonable discount [26]. Thus, this study proposed the following hypothesis.

H15. Post purchase promotion positively influences reuse intention.

\section{Research Method}

This study adopted survey to discuss the issues. To increase the reliability and the validity for each questionnaire item, a pilot test was conducted before the formal survey. The pilot test aimed to verify whether the reliability of the measurement is acceptable with Cronbach's $\alpha$ values as a standard $(\alpha \geq 0.7)$ or not. The questionnaire is firstly designed in English and then translated into Vietnamese. The pilot study shown that all question items are with qualified $\alpha$

\section{Analytical Results}

The analytical results show that there are some biases among the groups of demographics. There are $90 \%$ of the respondents aging less than 35 years old. $69 \%$ of them have bachelor degree, $51 \%$ are students, and $86 \%$ have monthly income which is lower than $\$ 1000$ USD. In addition, there is another bias that $70 \%$ of the respondents are male who accepted to answer survey's questionnaire. This bias might positively indicate that men are more interested in technology than women. The analytical results of formal survey shown that all $\alpha$ values are above 0.855 which is larger than 70 (Table 1). Thus, the consistency of this research is excellent at all. It means that the constructs are practical and consistent. The results of survey of favorite brand shows that Apple and Google (Android) are the most famous and popular STB of respondents and Apple is the most favorite in both countries Vietnam and Taiwan.

After the improvement from pre-test above, we conducted confirmatory factor analysis (CFA) for formal test with larger samples (more than 400 ones of each country) and find out that all the variables from surveying Vietnamese are valid. As for Taiwan, three items are invalid: PRO1, UF2 and GE3. The invalid items were eliminated and all left valid items were reserved for this formal test and conducted in CFA. The analytical results of CFA show that all variables are qualified for the other analysis.

According to [27], if Mardia's coefficient is lower than $p^{*}(p+2)$, where $p$ is the number of observed variables, then there is a multivariate normality. The results of normality analysis are as followings. 
Table 1 Cronbach's alpha coefficient of CFA

\begin{tabular}{|c|c|c|}
\hline Factor & Cronbach's alpha & Qualified \\
\hline \multicolumn{3}{|c|}{ Before purchase } \\
\hline Performance expectancy (PE) & 0.883 & Yes \\
\hline Effort expectancy (EE) & 0.923 & Yes \\
\hline Social influence (SI) & 0.965 & Yes \\
\hline Competitive products (CP) & 0.848 & Yes \\
\hline Price (PRI) & 0.960 & Yes \\
\hline Promotion (PRO) & 0.827 & Yes \\
\hline Behavioral intention (BI) & 0.936 & Yes \\
\hline Use intention (UI) & 0.885 & Yes \\
\hline \multicolumn{3}{|c|}{ After purchase } \\
\hline Usefulness of features (UF) & 0.948 & Yes \\
\hline Facilitating effects (FE) & 0.871 & Yes \\
\hline Connectedness $(\mathrm{CN})$ & 0.851 & Yes \\
\hline Access flexibility (AF) & 0.934 & Yes \\
\hline Application development (AD) & 0.895 & Yes \\
\hline Game experience (GE) & 0.958 & Yes \\
\hline Applications price (AP) & 0.806 & Yes \\
\hline Post purchase promotion (PPP) & 0.848 & Yes \\
\hline Reuse intention (RI) & 0.893 & Yes \\
\hline
\end{tabular}

\section{Before purchase}

Vietnam: multivariate coefficient $=295.026, \mathrm{p}=27$, then $\mathrm{p}^{*}(\mathrm{p}+2)=27 * 29=783$. Because $295.016<783$, it is normally distributed.

Taiwan: multivariate coefficient $=114.978, \mathrm{p}=26$, then $\mathrm{p}^{*}(\mathrm{p}+2)=26 * 28=728$.

Because $114.978<728$, it is a normal distribution.

\section{After purchase}

Vietnam: multivariate coefficient $=346.567, \mathrm{p}=33$, then $\mathrm{p}^{*}(\mathrm{p}+2)=33 * 35=$ 1155. Because $346.567<1155$, it is a normal distribution.

Taiwan: multivariate coefficient $=77.421, \mathrm{p}=34$, then $\mathrm{p}^{*}(\mathrm{p}+2)=31 * 33=1023$.

Because $77.421<1023$, it is normally distributed.

This study further adopted regression analyses were conducted for each of NTDA and TEL section below. 
After CFA, 4 independent variables (PE, EE, SI and CP) were used to check the influence of those factors to the factor "behavioral intention" (BI) and then 3 other independent variables (PRI, PRO and BI) were used to check the influence to the use intention of the model NTDA as follows:

\section{Vietnam}

\section{The influence of PE, EE SI and CP to BI:}

The Adjusted R Square is 0.144 (14.4\%). The p-value is smaller than 0.01. As for Collinearity Statistics, all the VIF values are $<2$, that satisfy the criterion. However, the p-values of PE and EE are $>0.05$, then they are eliminated. Based on the result, the model is built as follows:

$$
B I=0.221^{*} S I+0.178^{*} C P .
$$

Restated, $\mathrm{H} 3$ and $\mathrm{H} 4$ are supported, but not for $\mathrm{H} 1$ and $\mathrm{H} 2$. The SI and $\mathrm{CP}$ have impacts to behavioral intentions.

\section{The influence of PRI, PRO and BI to UI:}

The Adjusted R Square is $0.161(16.1 \%)$. The p-value is smaller than 0.01. As for Collinearity Statistics, all the VIF values are $<2$, that satisfy the criterion. However, the p-values of PRI $>0.05$, then it is eliminated. Based on the result, the fit model is as follows:

$$
U I=0.233^{*} P R O+0.246^{*} B I .
$$

Restated, H6 and H7 are supported, but not for H5. The PRO and BI has impacts to use intentions.

Finally, the general model is as follows:

$$
U I=0.233 * P R O+0.054 * S I+0.043 * C P .
$$

\section{Taiwan}

\section{The influence of PE, EE SI and CP to BI:}

The Adjusted R Square is 0.071 (7.1\%). The p-value is smaller than 0.01. As for Collinearity Statistics, all the VIF values are $<2$, that satisfy the criterion. However, the p-values of PE, EE and CP are > 0.05, then they are eliminated. Based on the result, the fit model is built as follows:

$$
B I=0.276^{*} S I .
$$

Restated, $\mathrm{H} 3$ is supported, but not for $\mathrm{H} 1, \mathrm{H} 2$, and $\mathrm{H} 4$. The SI has impacts to behavioral intentions.

\section{The influence of PRI, PRO and BI to UI:}

The Adjusted R Square is 0.157 (15.7\%). The p-value is smaller than 0.01. As for Collinearity Statistics, all the VIF values are $<2$, that satisfy the criterion. However, the p-values of PRI and BI are $>0.05$, then they are eliminated. Based on the result, the fit model is built as follows:

$$
U I=0.392 * P R O .
$$


Restated, only H6 is supported. The PRO has impacts to use intentions.

After CFA, 8 independent variables (UF, FE, CN, AF, AD, GE, AP and PPP) were used to check the influence to the factor of reuse intention) of the model TEL as follows:

\section{Vietnam}

The Adjusted R Square is $0.276(27.6 \%)$. The p-value is smaller than 0.01 which is accepted. As for Collinearity Statistics, all the VIF values are $<2$, that satisfy the criterion. However, the p-values of UF, FE, GE and PPP are $>0.05$, then they are eliminated from the model. Based on the result, the fit model is built as follows:

$$
R I=0.167 * C N+0.108 * A F+0.171 * A D+0.206 * A P .
$$

Restated, H10, H11, H12, and H14 are supported. The CN, AF, AD, and AP have impacts to reuse intentions.

\section{Taiwan}

The Adjusted R Square is 0.258 (25.8\%). In ANOVA analysis, the p-value is smaller than 0.01 which is accepted. As for Collinearity Statistics, all the VIF values are <2, that satisfy the criterion. However, the p-values of AF, PPP, UF and GE are > 0.05 , then they are eliminated. Based on the result, the fit model is built as follows:

$$
R I=0.116 * F E+0.116 * C N+0.183 * A D+0.108 * A P .
$$

Restated, H9, H10, H12, and H14 are supported. The FE, CN, AD, and AP have impacts to reuse intentions.

\section{Conclusion}

This study includes two main purposes on how users accept to use a new technology device, set top box, (for before purchase section) and evaluate users' feeling, loyalty after having experience on it (for after purchase section). Two research models (NTDA and TEL) are adopted for two analyses accordingly.

This study also pointed out that age and gender have significant influence on use and reuse intention over two countries. Generally, men are more interested in technology than women. Nowadays, young people who have more chances to access the Internet and the modernization are more well-informed about the new trend, it makes them more interested in technology compared to old people. As a result, young male customers are more likely to adopt technology device like set-top box rather than the others. Educational level and occupation have no influence on Vietnamese customer reuse intention, it seems that people of every education level and any occupations all love technological stuff and are going to use it again if they will have chance in the future. Income does not have influence on use intention, but it have influence on reuse intention in both Vietnam and Taiwan. They do not strongly care about the budget when intending to purchase set-top box, but for the repurchase, they (people with lower income) probably think it is sort of wasteful to use set-top box again or maybe the application price affects their intention negatively. 
This study also indicated the differences between Vietnam and Taiwan. Before purchase, contrary to the Vietnamese, the Taiwanese does not agree with the factors of social influence, price and use intention. In Vietnam, most of the people and family members did not owned set-top boxes, and they had not heard much information about the set-top box. The set-top box is not expensive and wasteful in the thinking of the Taiwanese. Interestingly, even though some Taiwanese have no experience on using set-top box, they think the set-top box is essential for the entertainment. The Taiwanese is strongly prone to pay for a set-top box in the future. Once they have a positive attitude for the set-top box, they will recommend it to the others.

Furthermore, customers preferred watching smart TV with the application system with variety of entertainment (music, social network, or news, ...). Customers are interested in the powerful hardware for entertainment, watch HD movies, chat Skype with others. Customers also want to use set-top box as a router and as a tool for saving data. Moreover, from a qualitative observation, customers love to synchronize files among their devices. For a successful synchronization, customers like to be loyal on the single brand of smart devices. For example, a smart device of Apple Inc. can be synchronized among other Apple devices using the same account. Customers love the portability of set-top box as well, convenient for people usually working on travel. Promotion is an important factor for attracting customers in both of the countries. Free shipment, discount and reliable stores make them confident to purchase the set-top box. Besides, users need the sustainable support for the software installation from the store's staff. The research results also show that promotion is the factor which has the most influence on use intention of both Vietnamese and Taiwanese.

After purchase, Vietnamese does not strongly satisfy with the post purchase promotion. There are only few stores selling set-top box give the chance to exchange the old device with the new one with reasonable price for the Vietnamese customers. They also do not usually see the valuable paid Apps which are free or discount on some special days. They are not satisfied with the trial version of the paid Apps that they want to have experience on it before purchase. Moreover, getting the gift code is not straightforward to them.

For connectedness, application development, and Apps price, both Vietnamese and Taiwanese agree with their impacts to reuse intention. For gamers, they feel that set-top box has become a significant part in game community. The services of set-top box Apps are good as well. User love the application system on set-top box like on the other smart devices. Various applications have been developed for set-top box platforms. Gamers found that set-top box is a cheap gaming machine compared to other ones but bringing them a great performance while playing game. Most of the gamers encourage manufacturers to extend game capability on set-top box so as to make game community more diversified and have a more competitive market compared to PlayStation and Xbox. The research indicates that Apps price is the factor which has the most influence on reuse intention of Vietnamese. For Taiwanese, the most influencing factor on reuse intentions is Apps development.

\section{Limitations and future study}

This is one of the first surveys to study about set-top box penetration into home console market. This survey also has several limitations. One of the inherent limitations includes inability to study more clearly and precisely, but it also partly 
expresses the acceptance of using a new technology device like set-top box and the feeling of customers after using it. Additionally, there are just a few home console devices such as PlayStation, Xbox, Apple TV box and Android TV box were mentioned, but the others were not included. It is just a study with the limited number of responses, most of respondents are young people and they are just male students. The further survey with a larger sample size and more factors influencing use and reuse intention should be included.

\section{REFERENCES}

[1] Alper, O., \& Metin, A. (2016). Licensed team merchandise buying behavior: a study on Turkish fans. Innovative Marketing, 2 (4), 117-129.

[2] Brunner, G. (2015). The Xbox One will feel more powerful in practice than it seems on paper. Retrieved from: http://www.extremetech.com/gaming/165918-th

[3] e-xbox-one-will-feel-more-powerful-in-practice-than-it-seems-on-paper."

[4] Bharatlal, K. (2013). Set top box, advantages, disadvantages. Retrieved from: http://whatisdigitization.blogspot.tw/2013/03/settopbox-digitization-advantagesdisavantages.html.

[5] Dang, X. T. (2011). AEC, ECFA and Vietnam-Taiwan Economic Relations. Taiwan-Vietnam Economic Cooperation: Moving Towards the 2015 Vision of ASEAN Economic Integration.

[6] Anwar, S., \& Nguyen, L. P. (2011). Foreign direct investment and trade: The case of Vietnam. Research in International Business and Finance, 25(1), 39-52.

[7] Su, H., \& Chang, S. C. (2015). New Television and Old Campaign: The Experience and Lessons in Digital Television Transition in Taiwan. International Journal of Journalism \& Mass Communication, 2(111), 1-7.

[8] Tran, H. P., Wang, F., Dewulf, J., Huynh, T. H., \& Schaubroeck, T. (2016). Estimation of the unregistered inflow of electrical and electronic equipment to a domestic market: a case study on televisions in Vietnam. Environmental Science \& Technology, 50(5), 2424-2433.

[9] Shim, Y., \& Shin, D. (2019). Smartness in techno-nationalism? Combining actor-network theory and institutionalization to assess Chinese smart TV development. Technological Forecasting and Social Change, 139(1), 87-98.

[10] Dang, Q. D. (2006). Set-top box connected with cable television system. Vietnam Posts and Telecommunications Group.

[11] Lin, C. L., Wang, P. C., \& Hou, T. W. (2008). A wrapper and broker model for collaboration between a set-top box and home service gateway. IEEE Transactions on Consumer Electronics, 54(3), 1123-1129.

[12] Wu, S. Y., Hung, S. C., \& Lin, B. W. (2006). Agile strategy adaptation in semiconductor wafer foundries: An example from Taiwan. Technological Forecasting and Social Change, 73(4), 436-451.

[13] Ju, H. C. \& Xiao, H. H. (2005). Family Network System Based on the STB. Airiti Library, 21(4), 464-466.

[14] Strangelove, M. (2015). Post-TV: Piracy, cord-cutting, and the future of television. University of Toronto Press.

[15] Gerhard, W., Hana, S. K. \& Sascha, S. (2016). Consumers' attitudes and intentions toward Internet-enabled TV shopping. Journal of Retailing and Consumer Services, 32 (1), 209-227.

[16] Chen, F. C., Kuo, Y. L. \& Annie, P. I. Y. (2014). User-experience of tablet operating system: An experimental investigation of Windows 8, iOS 6, and Android 4.2. Computers \& Industrial Engineering, 73 (1), 75-84. 
[17] Kamlesh, R., \& James, W. W. (1996). Set-top box control software: A key component in digital video. Philips Journal of Research, 50 (1/2), 185-199.

[18] Hsiao, K. L., \& Chen, C. C. (2015). What drives in-app purchase intention for mobile games? An examination of perceived values and loyalty. Electronic Commerce Research and Application, 16 (1), 18-29.

[19] Kottilingam, K. (2016). An improved database synchronization mechanism for mobile data using software-defined networking control. Computers \& Electrical Engineering, 53 (1), 88-99.

[20] Jan, P. V., Kwang, S. N. \& and Anand, A. (2011). Determinants of Willingness to Purchase Organic Food: An Exploratory Study Using Structural Equation Modeling. International Food and Agribusiness Management Review, 14 (2), 103-120.

[21] Andreas, K., \& Philip, S. (2014). Fixed costs per shipment. Journal of International Economics, 92 (1), 166-184.

[22] Veloutsou, C. (2015). Brand evaluation, satisfaction and trust as predictors of brand loyalty: the mediator-moderator effect of brand relationships. Journal of Consumer Marketing. 32(6), 405-421.

[23] Ann, D., Dimitri, V. R., Sofie, C., \& Ilse, D. B. (2014). A meta-analysis of serious digital games for healthy lifestyle promotion. Preventive Medicine, 69 (1), 95-107.

[24] Ibrahim, A. (2016). Understanding and predicting students' intention to use mobile cloud storage services. Computers in Human Behavior, 58 (1), 150-157.

[25] Messaoudi, F., Ksentini, A., Simon, G., \& Bertin, P. (2017). Performance analysis of game engines on mobile and fixed devices. ACM Transactions on Multimedia Computing, Communications, and Applications (TOMM), 13(4), $1-28$.

[26] Kristen, R. W. J. (2014). Exploiting Hardware Monitoring in Software Engineering. Advances in Computers, 93 (1), 53-101.

[27] (Samuel et al., 2016)

[28] Mahmoudi, A. \& Shavandi, H. (2013). Analyzing price, warranty length, and service capacity under a fuzzy environment: Genetic algorithm and fuzzy system. Scientia Iranica, 20 (3), 975-982.

[29] Bollen, K. A. (1989). A new incremental fit index for general structural equation models. Sociological methods \& research, 17(3), 303-316. 

